\title{
Establishing Functional Residual Capacity at Birth: The Effect of Sustained Inflation and Positive End-Expiratory Pressure in a Preterm Rabbit Model
}

\author{
ARJAN B. TE PAS, MELISSA SIEW, MEGAN J. WALLACE, MARCUS J. KITCHEN, ANDREAS FOURAS, ROBERT A. LEWIS, \\ NAOTO YAGI, KENTARO UESUGI, SUSAN DONATH, PETER G. DAVIS, COLIN J. MORLEY, AND STUART B. HOOPER
}

Neonatal Services [A.B.P., P.G.D., C.J.M.], Royal Women's Hospital, Melbourne, Victoria 3052, Australia; Department of Pediatrics [A.B.P.], Leiden University Medical Center, Leiden, 2300 RC, Netherlands; Department of Physiology [M.S., M.J.W., S.B.H.], School of

Physics [M.J.K.], Monash Centre for Synchrotron Science [R.A.L.], Division of Biological Engineering [A.F.], Monash University, Melbourne, Victoria 3800, Australia; SPring-8/JASRI [N.Y., K.U.], Sayo, Hyogo 679-5198, Japan; Murdoch Children's Research Institute [S.D.], Melbourne, Victoria 3052, Australia

\begin{abstract}
The effect of a 20 s sustained inflation (SI) and positive end-expiratory pressure (PEEP) on functional residual capacity (FRC) formation at birth were investigated. Preterm rabbit pups $(28 \mathrm{~d})$ were randomized at birth into four groups ( $n=6$ for each): 1) SI, PEEP $5 \mathrm{~cm}$ $\mathrm{H}_{2} \mathrm{O}$, 2) no SI, PEEP $5 \mathrm{~cm} \mathrm{H}_{2} \mathrm{O}, 3$ ) no SI + no PEEP, 4) $\mathrm{SI}+$ no PEEP. FRC and tidal volume $(\mathrm{Vt})$ were measured by plethysmography and uniformity of lung aeration by phase contrast $\mathrm{X}$-ray imaging. Ventilation with a SI and PEEP uniformly aerated the lung and Vt and FRC were recruited by the first tidal inflation. Ventilation without a SI, with PEEP, gradually recruited Vt and FRC with each inflation but aeration was not uniform. Ventilation without a SI or PEEP, gradually recruited Vt, but no FRC. Ventilation with a SI, without PEEP, uniformly aerated the lung and recruited Vt but no FRC. FRC was greater with SI ( $p=0.006)$ during the first minute, but was larger with PEEP than without PEEP throughout the first 7 min $(p<0.0005)$. Effects of PEEP and SI were additive. In ventilated preterm rabbits at birth, combining a SI and PEEP improved FRC formation and uniformity of lung aeration, but PEEP had the greatest influence. (Pediatr Res 65: 537-541, 2009)
\end{abstract}

$\mathrm{T}^{\mathrm{s}}$ There is currently little specific evidence about the appropriate respiratory support for very preterm infants immediately after birth (1). Ventilatory strategies in the delivery room may play an important role in the development or prevention of lung injury (2-6) as inappropriate ventilatory support during resuscitation can cause lung damage (2,3,7-11).

Adequate gas exchange requires the rapid creation and maintenance of a functional residual capacity (FRC). Many preterm infants need positive pressure ventilation to aerate their lungs and overcome the high surface tension and frictional forces caused by liquid-filled airways. Initiating respiratory support with a sustained inflation (SI) may improve

Received September 23, 2008; accepted December 17, 2008

Correspondence: Arjan B. te Pas, M.D., Department of Pediatrics, Leiden University Medical Center, J6-S, PO Box 9600, 2300 RC Leiden, The Netherlands; e-mail: a.b.te_pas@lumc.nl

Support was provided by SPring- 8 synchrotron facility (Japan), granted under the approval of the SPring-8 Program Review Committee (proposal nos. 2006B0002, 2007A0002).

A.B.P. is a recipient of a Ter Meulen Fund grant for working visits, Royal Netherlands Academy of Arts and Sciences, The Netherlands and recipient of a Royal Women's Hospital postgraduate scholarship. M.J.K. is a recipient of an ARC Post-Doctoral Fellowship.
FRC development by allowing an appropriate time-constant for the air/liquid interface to move into the distal airways. Although clinical studies have shown lower intubation rates when a SI is given $(4,6,12)$, there is only one study evaluating the physiology of a SI in establishing an FRC in humans (13).

Once the lung is aerated and airway liquid is cleared, the low compliance of the immature lung results in a very short expiratory time constant and the lung easily loses FRC. However, the creation and maintenance of an FRC during resuscitation of preterm infants is assisted by a positive endexpiratory pressure (PEEP), which reduces distal airway collapse at end expiration $(14,15)$. Although PEEP is always used during ventilation in the neonatal unit, international resuscitation guidelines provide few recommendations on the use of PEEP immediately after birth $(1,16)$.

We have used simultaneous phase contrast $\mathrm{X}$-ray imaging and plethysmography to examine the effect of PEEP and a $20 \mathrm{~s}$ SI on the spatial pattern of lung aeration and FRC recruitment in a preterm rabbit model. We hypothesized that the combination of a $20 \mathrm{~s}$ SI followed by ventilation with PEEP would produce a larger FRC than either a 20 s SI or PEEP alone or neither PEEP nor a SI.

\section{METHODS}

Animal experiments. All animal procedures were approved by the SPring- 8 Animal Care and Monash University's School of Biomedical Science's Animal Ethics Committees. Studies were conducted in experimental hutch 3 of beam line 20B2, in the Biomedical Imaging Centre at the SPring-8 synchrotron in Japan.

Experiments were performed on six litters of New Zealand White rabbits using 35 pups delivered at 28-d gestation (term $32 \mathrm{~d} ; 28 \mathrm{~d}$ correlates approximately with human infants of 26-28 wk of gestation). The does were anesthetized (Propofol; $12 \mathrm{mg} / \mathrm{kg}$ bolus, $100 \mathrm{mg} / \mathrm{kg} / \mathrm{h}$ i.v. infusion, then isofluorane 1 to $2 \%$ ), intubated, and ventilated. The pups were sequentially delivered by hysterotomy, leaving the fetal membranes over the nose and mouth to prevent air entering the lungs. The pups were sedated (Nembutal $0.1 \mathrm{mg}$ intraperitoneal), and a topical anesthetic (5\% xylocaine) was applied and an endotracheal tube (18 gauge plastic catheter) inserted via tracheostomy; the endotracheal tube was blocked to prevent air from entering the lung before imaging commenced. The fetal membranes were then removed, the umbilical

\footnotetext{
Abbreviations: FRC, functional residual capacity; PEEP, positive endexpiratory pressure; PPV, positive pressure ventilation; SI, sustained inflation; $\mathbf{V t}$, tidal volume
} 
cord ligated, and cut and the pup was placed in a water-filled plethysmograph (see later). The pups were then ventilated for $7 \mathrm{~min}$ while they were simultaneously imaged. After the experiment, pups were killed by anesthetic over dose.

Plethysmography. Lung gas volume changes were measured using waterbased plethysmography (17). The pup was placed in the plethysmograph (head out), which consisted of a sealed water-filled $\left(37^{\circ} \mathrm{C}\right)$ perspex chamber open to the atmosphere via a water column. The head of the pup was located outside the chamber and a rubber diaphragm formed a watertight seal around the neck of the pup. The increase in lung volume caused by ventilation displaced water from the chamber into the water column and the resulting increase in pressure was recorded electronically using a computerized data acquisition system (Powerlab, ADInstruments Sydney, Australia). The plethysmograph was calibrated before each experiment by measuring the pressure change caused by injecting a known volume of water $(1 \mathrm{~mL})$ into the sealed chamber. We recorded FRC, initial volume, tidal volume (Vt), airway pressure, and gas flow.

Mechanical ventilation. A purpose-built small animal ventilator was used to ventilate pups with air in a time cycled, pressure-limited mode (positive pressure ventilation, PPV). Ventilation started with a PIP of $35 \mathrm{~cm} \mathrm{H}_{2} \mathrm{O}$ and an inspiration time of 1 or $20 \mathrm{~s}$, depending on the group (see later). After the first inflation, pups were ventilated with a fixed inspiration and expiration time (rate 24/min, 1:1.5 inspiration: expiration ratio), starting with a peak inspiratory pressure of $35 \mathrm{~cm} \mathrm{H}_{2} \mathrm{O}$ which was then adjusted (increased or decreased by $2 \mathrm{~cm} \mathrm{H}_{2} \mathrm{O}$ per minute) to generate a $\mathrm{Vt}$ of $\sim 10 \mathrm{~mL} / \mathrm{kg}$, PEEP was set at either 0 or $5 \mathrm{~cm} \mathrm{H}_{2} \mathrm{O}$.

Protocol. The pups were randomly allocated to one of the following four ventilation groups:

Group 1: SI for $20 \mathrm{~s}$ followed by PPV with PEEP $5 \mathrm{~cm} \mathrm{H} \mathrm{H}_{2} \mathrm{O}$ (20 SI + PEEP). Group 2: PPV with PEEP $5 \mathrm{~cm} \mathrm{H}_{2} \mathrm{O}$ (No SI + PEEP).

Group 3: PPV with PEEP $0 \mathrm{~cm} \mathrm{H}_{2} \mathrm{O}$ (No SI + no PEEP).

Group 4: SI for $20 \mathrm{~s}$ followed by PPV with PEEP $0 \mathrm{~cm} \mathrm{H}_{2} \mathrm{O}(20 \mathrm{SI}+$ no PEEP).

Phase contrast $x$-ray imaging. Phase contrast $\mathrm{x}$-ray imaging was used to image the effect of a SI and PEEP on the rate and spatial pattern of lung aeration. Details describing the imaging procedures have been reported previously $(18,19)$. Briefly, the x-ray energy used was $24 \mathrm{keV}$, and the pups were located $2.0 \mathrm{~m}$ upstream of the detector (Hamamatsu, C4742-95HR) and a short exposure time $(50 \mathrm{~ms})$ and a relatively long inflation time $(1 \mathrm{~s})$ were used to minimize motion blur. Image acquisition was synchronized with, and triggered by, the ventilator (onset of inflation), which triggered a sequence of images at $300 \mathrm{~ms}$ intervals. A preobject shutter prevented radiation exposure between image acquisitions and the timing of each image acquisition was recorded digitally in unison with the plethysmograph recording.

The uniformity of lung aeration was measured by dividing the images into quadrants and measuring the air volume in each quadrant (at end expiration or during the SI) using a phase retrieval analysis (17). This analysis has recently been validated (17) and uses extrathoracic landmarks to track pup movement between consecutive images to ensure that the relative amount of lung in each quadrant does not change over time. However, as the amount of lung (thus potential air volume) varies between quadrants, the air volume of each quadrant at each time point was expressed as a percentage of the maximum volume achieved in that quadrant after complete lung aeration. The uniformity of lung aeration for each pup was then measured by determining the coefficient of variation in relative air volume between all four quadrants.

Analysis. FRC was defined as the volume of air remaining in the lung at end expiration. Vt recruitment refers to the gradual increase in Vt with time for a given pressure gradient.

At $20 \mathrm{~s}, 1,3$, and $7 \mathrm{~min}$, we calculated the average FRC over four consecutive inflations. For each group, we used the area under the FRC time curve (FRC-time integral) to calculate the time-related increase in FRC between 0 and $1 \mathrm{~min}$ and during the total ventilation period $(0-7 \mathrm{~min})$. FRC at start of ventilation was assumed to be zero. One minute was used as this is a critical time point during neonatal resuscitation when decisions are made about modes of respiratory support (1). To compare the increase in FRC-time integral (area under curve) between groups in the two time periods and to see which variable (SI or PEEP) influenced FRC most, or if there was interaction between the two variables, we performed a linear regression analysis and adjusted for the possible clustering effect of several pups having the same mother (24 pups, six different mothers). Significance was defined as $p<0.05$. Statistical analyses were performed using Stata software (Stata 10 for Windows).

\section{RESULTS}

Animal data. Twenty-seven of 35 pups were delivered alive and studied, of which three were excluded because of equip- ment malfunctions $(n=2)$ and endotracheal tube obstruction $(n=1)$. None of the pups developed a pneumothorax, as determined by observation of the images. The average (SD) weight was as follows: group 1 (20 SI + PEEP) $37.9 \pm 2.3 \mathrm{~g}$, group 2 (no SI + PEEP) $34.4 \pm 2.4 \mathrm{~g}$, group 3 (no SI + no PEEP) $37.3 \pm 1.5 \mathrm{~g}$, group 4 (20 SI + no PEEP) $39.9 \pm$ $11.3 \mathrm{~g}$. Each group contained six pups.

The lung gas volume changes with ventilation onset were very different between groups (Fig. 1). In group 1 (20 SI + PEEP), lung gas volumes rapidly increased and, although different regions aerated at different rates, by the end of the SI, the lung was uniformly aerated (Figs. 1-3). Indeed, the coefficient of variation in relative air volumes across the lung (Fig. 3) decreased from $27.9(12.7) \%$ at $2.5 \mathrm{~s}$ to $0.7(0.6) \%$ at $20 \mathrm{~s}$. As a result, following a SI (Figs. $1 A$ and $D$ ), the Vt did not increase with time and the Vt was fully recruited (Fig. 4). Neither the Vt nor FRC increased further with subsequent ventilation (Table 1; Figs. 1 and 4).

In group 2 (no SI + PEEP), the Vt gradually increased with each inflation (Fig. 4) as did the FRC (Fig. 1, Table 1), although the FRC (Table 1) and uniformity of lung aeration (Figs. 2 and 3) was markedly less than in group 1 (20 SI + PEEP) at $20 \mathrm{~s}$. Although the coefficient of variation in relative air volumes
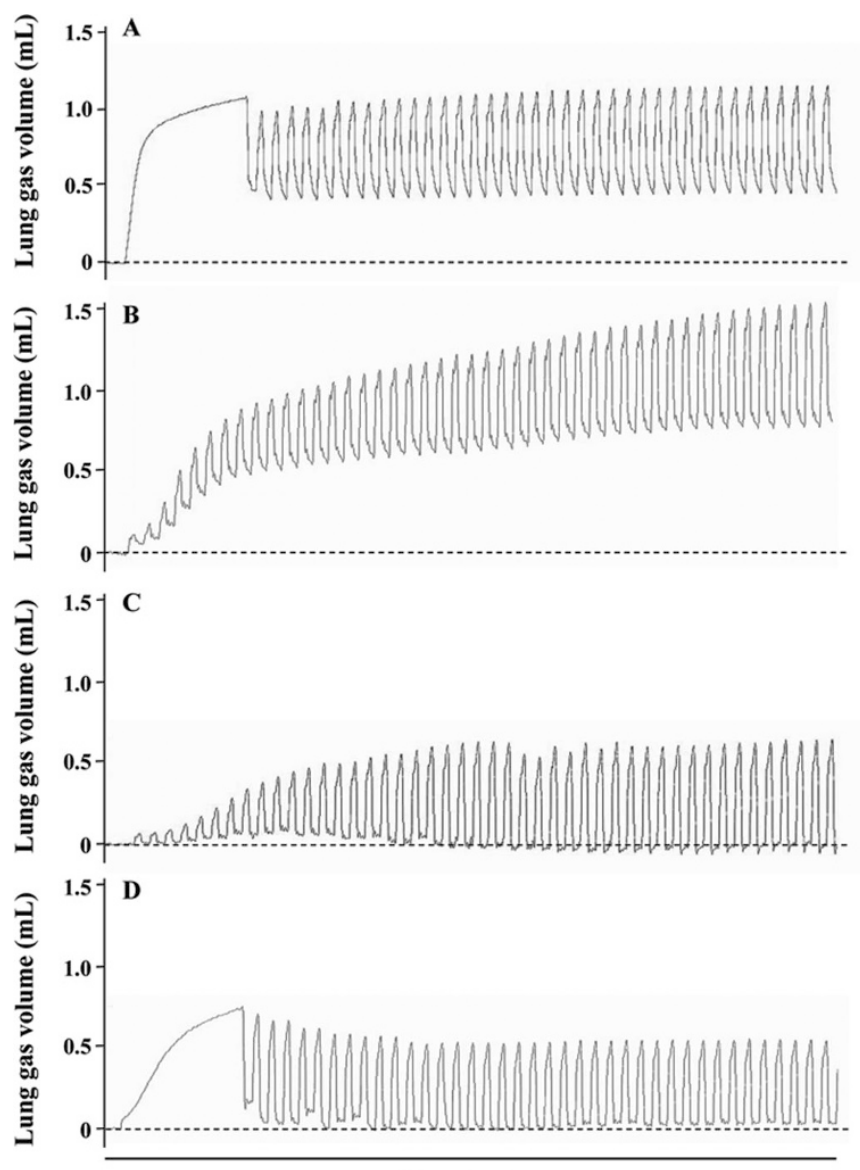

Time 2mins

Figure 1. Representative examples of recordings from each group. Change in lung gas volume from birth in anesthetized ventilated preterm rabbit pups using plethysmography. With PEEP ( $A$ and $B$ ), an end-expiratory gas volume (FRC) was rapidly formed whereas in the absence of PEEP a significant FRC was not formed $(C$ and $D)$. 

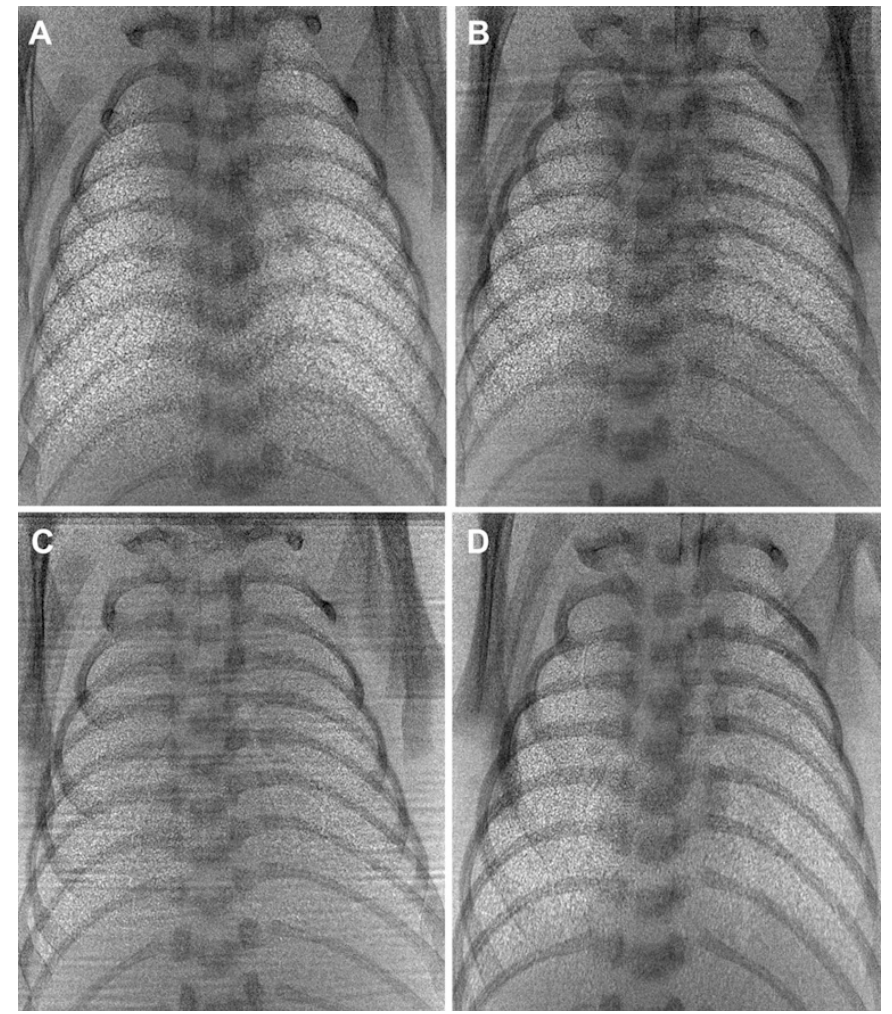

Figure 2. Representative examples of phase contrast $x$-ray images from each group. Images were acquired at end expiration (FRC) $20 \mathrm{~s}$ after birth in anesthetized preterm rabbit pups in which an initial SI of $20 \mathrm{~s}$ or not was given and ventilated in the presence/absence of PEEP $\left(5 \mathrm{~cm} \mathrm{H}_{2} \mathrm{O}\right)$. SI + PEEP $(A)$, no SI $+\operatorname{PEEP}(B)$, no SI + no $\operatorname{PEEP}(C), \mathrm{SI}+$ no $\operatorname{PEEP}(D)$.

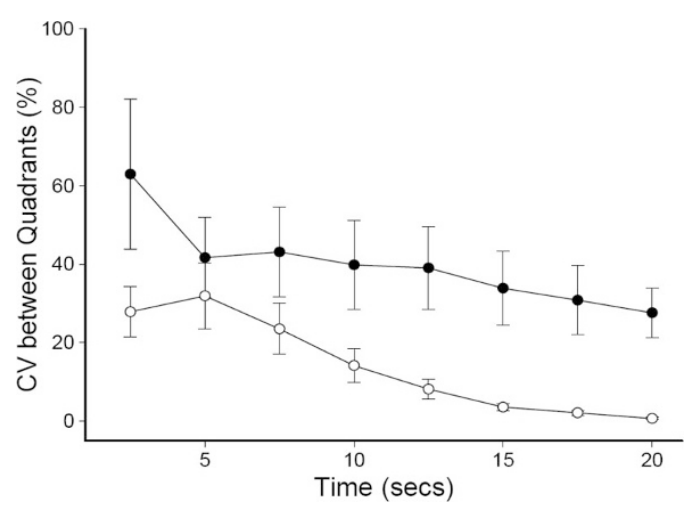

Figure 3. Uniformity of lung aeration was assessed by measuring the coefficient of variation in air volume across four different regions of the lung. Pups were ventilated either with a $20 \mathrm{~s}$ sustained inflation (group 1; $\bigcirc$ ) or without a SI but with $5 \mathrm{~cm} \mathrm{H}_{2} \mathrm{O}$ PEEP (group 2; )); measurements were made at either end expiration (no SI) or during the SI. Aeration across the lung was significantly more variable (less uniform) without a SI, compared with ventilation with a SI. After $15 \mathrm{~s}$ of a SI, the lung was uniformly aerated as indicated by little variability in relative air volume between lung regions.

across the lung (Fig. 3) decreased from $63.0(38.3) \%$ at $2.5 \mathrm{~s}$ to $27.6(12.6) \%$ at $20 \mathrm{~s}$ in group 2 , it remained significantly greater than in group 1 pups throughout this period.

In group 3 (no SI + no PEEP), the Vt gradually increased as in group 2 (Fig. 4), but a significant FRC failed to develop (Figs. 1-2, Table 1).

In group 4 (20 SI + no PEEP), the lung gas volume rapidly increased during the SI as in group 1. However, after the SI

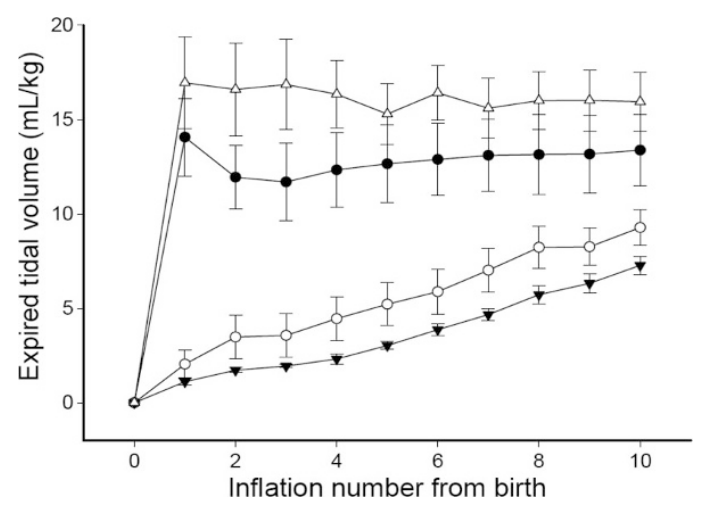

Figure 4. Effect of a $20 \mathrm{~s}$ SI and $5 \mathrm{~cm} \mathrm{H}_{2} \mathrm{O}$ PEEP on tidal volume recruitment after birth. In absence of a SI, tidal volume was recruited gradually with each subsequent inflation, whereas a $20 \mathrm{~s}$ SI fully recruited tidal volume. SI $+\operatorname{PEEP}(\bullet)$, no SI $+\operatorname{PEEP}(\bigcirc)$, no SI + no PEEP $(\boldsymbol{\nabla})$, SI + no PEEP $(\triangle)$.

Table 1. Mean (SD) FRC in time of the groups

\begin{tabular}{lrrrr}
\hline & \multicolumn{4}{c}{ FRC $(\mathrm{mL} / \mathrm{kg})$} \\
\cline { 2 - 5 } \multicolumn{1}{c}{ Group } & \multicolumn{1}{c}{$20 \mathrm{~s}$} & \multicolumn{1}{c}{$1 \mathrm{~min}$} & \multicolumn{1}{c}{$3 \mathrm{~min}$} & \multicolumn{1}{c}{$7 \mathrm{~min}$} \\
\hline 20 SI + PEEP & $10.8(3.5)$ & $10.8(3.3)$ & $11.2(3.5)$ & $11.7(3.4)$ \\
No SI + PEEP & $7.5(5.7)$ & $9.3(6.1)$ & $8.8(6.6)$ & $8.4(7.3)$ \\
No SI + no PEEP & $0.9(1.0)$ & $-0.3(1.4)$ & $-1.2(2.9)$ & $-0.9(2.5)$ \\
20 SI + no PEEP & $2.5(2.3)$ & $1.5(2.1)$ & $2.2(1.9)$ & $2.3(1.3)$ \\
\hline
\end{tabular}
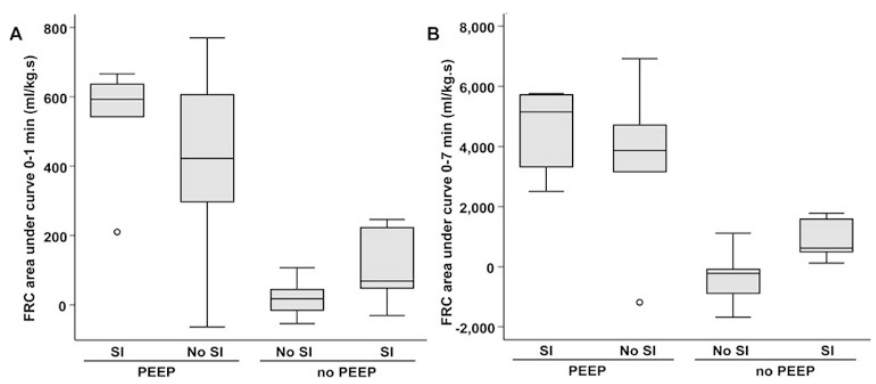

Figure 5. FRC area under curve (median $(\mathrm{IQR})$ ) in anesthetized ventilated preterm rabbit pups in the presence/absence of $5 \mathrm{~cm} \mathrm{H}_{2} \mathrm{O}$ PEEP, with/without a $20 \mathrm{~s}$ SI from 0 to $1 \mathrm{~min}(A)$ and 0 to $7 \mathrm{~min}(B)$.

the lungs were unable to retain an FRC (Figs. 1 and 2, Table 1), although the Vt was fully recruited (Fig. 4).

FRC time-integral: Zero to 1 min. The FRC time-integral from 0 to 1 min after birth (Fig. 5A) was larger when a $20 \mathrm{~s}$ SI was used compared with no SI ( $\beta$ coefficient $108 ; p=$ 0.006). Compared with when no PEEP was used, the increase in the FRC-time integral was always larger when PEEP was used ( $\beta$ coefficient $413 ; p=0.003$ ). There was no interaction between PEEP and the $20 \mathrm{~s} \mathrm{SI}(\mathrm{p}$ value for interaction $=0.5$ ), indicating that the effects of PEEP and SI on the FRC-time integral were additive (Fig. 5A).

FRC time-integral: Zero to $7 \mathrm{~min}$. The FRC time-integral from 0 to $7 \mathrm{~min}$ after birth (Fig. $5 B$ ) tended to be larger when a 20 s SI was used compared with no SI ( $\beta$ coefficient 1120 ; $p=0.06$ ), although the difference was not quite statistically significant. Compared with no PEEP, the FRC-time integral was much larger when PEEP was used ( $\beta$ coefficient 3808; $p<$ $0.0005)$. There was no interaction between PEEP and the 20 s SI 
on the FRC-time integral ( $p$ value for interaction $=0.8$ ), again indicating that the effects of PEEP and SI were additive (Fig. $5 B$ ).

\section{DISCUSSION}

This study has shown that with sedated, ventilated, preterm rabbit pups, in the first $7 \mathrm{~min}$ after birth, a larger FRC was created and maintained when a $20 \mathrm{~s}$ SI was followed by ventilation with $5 \mathrm{~cm} \mathrm{H}_{2} \mathrm{O}$ PEEP compared with either no SI or no PEEP. PEEP had a larger effect on the formation of FRC than a SI inflation. However, the effects of SI and PEEP were additive, making it possible to create and maintain an FRC as early as the first inflation, if it is sustained. In absence of PEEP, the lungs failed to retain an FRC, irrespective of whether a SI was used, although a SI produced uniform lung aeration before onset of tidal ventilation. This emphasizes the importance of using PEEP during ventilation at birth in very preterm infants and indicates that a combination of the two techniques (PEEP + SI) may be better, particularly in infants with very immature lungs. Indeed, a SI can promote uniform lung aeration from the first inflation, whereas the addition of PEEP helps to maintain FRC in the lung.

The FRC levels required by preterm infants to establish adequate gas exchange at birth are unclear. However, the FRC we measured in preterm rabbit pups exposed to a $20 \mathrm{~s}$ SI with PEEP was comparable to the average FRC measured at birth in spontaneously breathing term rabbit pups $(10-15 \mathrm{~mL} / \mathrm{kg})$ (20). Vyas et al. $(21,22)$ and Milner et al. (23)measured FRCs of $5-6 \mathrm{~mL} / \mathrm{kg}$ in the first few breaths of spontaneously breathing term infants. A similar FRC was measured in asphyxiated infants during resuscitation with a 5-s inflation (13), whereas no FRC was created without an initial long inflation (24). In both studies, no PEEP was used, which may have affected the development of FRC.

After birth, uniform lung aeration and the retention of an appropriate FRC are required to facilitate effective gas exchange and improve an infant's oxygenation and heart rate. We have shown that a combined $20 \mathrm{~s}$ SI and PEEP produced a larger FRC during the first minutes after birth. This could explain why intubation rates in very preterm infants are lower in the delivery room when a SI was given, followed by continuous positive airway pressure $(4,6,12)$.

Healthy, term infants rapidly create an FRC during their first breaths by exerting large intrathoracic subatmospheric pressures $(25,26)$. However, preterm infants often have problems clearing lung liquid and need help to overcome high frictional forces caused by airway liquid. As a result, either a large pressure gradient (inflating pressure) or a greater duration of inflation is required to move the air/liquid interface into the distal airways. For any given inflating pressure, if the duration of inflation is too short, the air/liquid interface will not reach the gas exchange regions. As application of high airway pressures may be injurious, a long initial inflation may be preferential, allowing time for air to enter alveoli (13). Indeed, the first breaths of spontaneously breathing infants are characterized by a long deep breath followed by a prolonged expiratory phase $(27,28)$. The phase contrast $\mathrm{x}$-ray imaging analysis clearly demonstrated that, at the end of a $20 \mathrm{~s} \mathrm{SI}$, the lung was uniformly aerated, with very little variation $(<1 \%$; Fig. 3$)$ in relative air volumes across the lung.
As a result, when tidal ventilation commenced, ventilation seemed to occur uniformly throughout the lung. In the absence of a SI, lung aeration was gradual and regionalized, restricting tidal ventilation to small regions of the lung initially. This is likely to be injurious, particularly if high pressures and short inspiratory times are used, as these regions will be the most compliant and prone to over-expansion.

After lung liquid clearance, a surfactant deficient immature lung has a low compliance and tends to collapse at end expiration when PEEP is not used. We found that, although the effects of a SI and PEEP were additive, PEEP had a much greater influence on FRC formation than a SI. Indeed, independent of whether a SI was given or not, no FRC was created if PEEP was not used. This is consistent with previous data suggesting that, during resuscitation at birth, PEEP is necessary in immature lungs to establish and maintain FRC $(14,15)$ and improve oxygenation $(29,30)$. No randomized trials have evaluated the role of PEEP or no PEEP during resuscitation in the delivery room $(31,32)$.

In some pups ventilated without PEEP, the FRC decreased slightly below zero (Table 1), which occurred after an initial transient increase. Although the reason for this is unclear, it was not caused by lung aeration before the onset of ventilation and is likely to be an experimental artifact. Although the weight of water on the chest wall may have slightly increased deflation forces on the lung, particularly in the absence of PEEP, it cannot explain a decrease in FRC below zero in these pups. Another possible explanation is a small upward displacement of the pups within the plethysmograph after ventilation onset, although this could not be confirmed from the images.

There was much individual variation in FRC within a group, especially in pups receiving PEEP but no SI (group 2; Table 1); this is also reflected by the high variability in relative air volumes across the lung in this group (Fig. 3). The variability between pups may be caused by the natural variation in maturity at $28 \mathrm{~d}$, which is also influenced by the time of day the experiments were done. It is interesting that the variability in FRC was significantly lower in the SI group compared with no SI (coefficient of variation $=30.8(1.2) \%$ versus $75.9(7.5) \% ; p<0.001)$, despite similar levels of expected variability in pup maturation (Table 1). This is most likely due to the greater uniformity and degree of lung aeration achieved before the onset of tidal ventilation (Fig. 3). It is possible that a $20 \mathrm{~s} \mathrm{SI}$ at $35 \mathrm{~cm} \mathrm{H}_{2} \mathrm{O}$ was enough to overcome all the different factors that contribute to the time constant for lung aeration, leading to less variation in FRC. This indicates that a SI may be able to achieve a consistently higher FRC when used with PEEP and that a SI may have major benefits in very immature lungs, but is of less benefit in more mature lungs. Indeed, we observed this difference in two very small $(\sim 25-30 \mathrm{~g})$ pups with very stiff lungs. The pup ventilated with PEEP alone, failed to increase its FRC to a level seen in larger pups (movie 1 on http://www.physics.monash.edu.au/research/ news/lungxray.html). However, ventilation with a SI + PEEP in the other pup caused aeration of the apical lobes before the onset of tidal ventilation), resulting in the recruitment of a larger FRC (movie 2 on http://www.physics.monash.edu.au/research/news/ lungxray.html). 
Although our model is not directly applicable to preterm infants, our study was designed to specifically assess the affects of SI and PEEP on the formation of FRC in preterm lungs from birth. Preterm pups were all born by caesarean section so that we could image and record the first inflation, and antenatal steroids were not administered to maximize differences between the groups. Spontaneous breathing was inhibited to assess the affects of PEEP and SI. Pups were ventilated in an upright position in water to simultaneously image and measure lung gas volumes. Although it would not be possible to perform such experiments in very preterm infants, we would expect similar results. Indeed, similar studies were done with preterm rabbits to initially demonstrate the efficacy of surfactant treatment $(33,34)$.

The inflating pressure $\left(35 \mathrm{~cm} \mathrm{H}_{2} \mathrm{O}\right)$ and length of SI used were based on earlier observations in preterm pups. As phase contrast $\mathrm{x}$-ray imaging is ideal for detecting pneumothoraces, we can confirm that no pups developed pneumothoraces in the first $7 \mathrm{~min}$. The plethysmography data also demonstrated that a SI did not cause lung over-expansion as the gas volumes achieved were not different from the volumes achieved at end inspiration during ventilation with PEEP and a Vt of $\sim 10 \mathrm{~mL} / \mathrm{kg}$. However, as most preterm infants breathe at birth and the lung may be partially aerated, the use of fixed inflating pressures is problematic as the starting gas volume is unknown. Similarly, the application of a sustained fixed inflation pressure in the presence of breathing may be inadvisable and could lead to considerable lung over-expansion (2). It is likely that different inflation pressures and times, with a maximum limit placed on the volume inhaled, may be preferential in preterm infants.

In conclusion, we have shown that both a $20 \mathrm{~s}$ SI and $5 \mathrm{~cm}$ $\mathrm{H}_{2} \mathrm{O}$ of PEEP promote uniform lung aeration and create a much larger FRC at birth than ventilation without these techniques. A $20 \mathrm{~s}$ initial SI resulted in uniform lung aeration before the onset of tidal ventilation, allowing subsequent tidal ventilation to be uniformly distributed throughout the lung. PEEP was essential to maintain FRC both with and without a SI. The effects of PEEP and SI were additive for the creation of FRC. Following a SI the variability in FRC during treatment with PEEP was greatly reduced. It is possible that combining these two techniques during stabilization of preterm infants would increase the chance of establishing effective breathing, promote uniform ventilation and reduce the need for intubation in the delivery room.

\section{REFERENCES}

1. International Liaison Committee on Resuscitation 2006 The International Liaison Committee on Resuscitation (ILCOR) consensus on science with treatment recommendations for pediatric and neonatal patients: neonatal resuscitation. Pediatrics 117:e978-e988

2. Bjorklund LJ, Ingimarsson J, Curstedt T, John J, Robertson B, Werner O, Vilstrup CT 1997 Manual ventilation with a few large breaths at birth compromises the therapeutic effect of subsequent surfactant replacement in immature lambs. Pediatr Res 42:348-355

3. Wada K, Jobe AH, Ikegami M 1997 Tidal volume effects on surfactant treatment responses with the initiation of ventilation in preterm lambs. J Appl Physiol 83:1054-1061

4. Lindner W, Vossbeck S, Hummler H, Pohlandt F 1999 Delivery room management of extremely low birth weight infants: spontaneous breathing or intubation? Pediatrics 103:961-967
5. Aly H, Massaro AN, Patel K, El Mohandes AA 2005 Is it safer to intubate premature infants in the delivery room? Pediatrics 115:1660-1665

6. te Pas AB, Walther FJ 2007 A randomized, controlled trial of delivery-room respiratory management in very preterm infants. Pediatrics 120:322-329

7. Jobe AH, Kramer BW, Moss TJ, Newnham JP, Ikegami M 2002 Decreased indicators of lung injury with continuous positive expiratory pressure in preterm lambs. Pediatr Res 52:387-392

8. Thomson MA, Yoder BA, Winter VT, Martin H, Catland D, Siler-Khodr TM, Coalson JJ 2004 Treatment of immature baboons for 28 days with early nasal continuous positive airway pressure. Am J Respir Crit Care Med 169:1054-1062

9. Bjorklund LJ, Ingimarsson J, Curstedt T, Larsson A, Robertson B, Werner O 2001 Lung recruitment at birth does not improve lung function in immature lambs receiving surfactant. Acta Anaesthesiol Scand 45:986-993

10. Ingimarsson J, Bjorklund LJ, Curstedt T, Gudmundsson S, Larsson A, Robertson B, Werner O 2004 Incomplete protection by prophylactic surfactant against the adverse effects of large lung inflations at birth in immature lambs. Intensive Care Med 30:1446-1453

11. Ikegami M, Kallapur S, Michna J, Jobe AH 2000 Lung injury and surfactant metabolism after hyperventilation of premature lambs. Pediatr Res 47:398-404

12. Lindner W, Hogel J, Pohlandt F 2005 Sustained pressure-controlled inflation or intermittent mandatory ventilation in preterm infants in the delivery room? A randomized, controlled trial on initial respiratory support via nasopharyngeal tube. Acta Paediatr 94:303-309

13. Vyas H, Milner AD, Hopkin IE, Boon AW 1981 Physiologic responses to prolonged and slow-rise inflation in the resuscitation of the asphyxiated newborn infant. J Pediatr 99:635-639

14. Upton CJ, Milner AD 1991 Endotracheal resuscitation of neonates using a rebreathing bag. Arch Dis Child 66:39-42

15. Naik AS, Kallapur SG, Bachurski CJ, Jobe AH, Michna J, Kramer BW, Ikegami M 2001 Effects of ventilation with different positive end-expiratory pressures on cytokine expression in the preterm lamb lung. Am J Respir Crit Care Med 164:494-498

16. Morley C 2007 New Australian Neonatal Resuscitation Guidelines. J Paediatr Child Health 43:6-8

17. Kitchen MJ, Lewis RA, Morgan MJ, Wallace MJ, Siew ML, Siu KK, Habib A, Fouras A, Yagi N, Uesugi K, Hooper SB 2008 Dynamic measures of regional lung air volume using phase contrast X-ray imaging. Phys Med Biol 53:6065-6077

18. Hooper SB, Kitchen MJ, Wallace MJ, Yagi N, Uesugi K, Morgan MJ, Hall C, Siu KK, Williams IM, Siew M, Irvine SC, Pavlov K, Lewis RA 2007 Imaging lung aeration and lung liquid clearance at birth. FASEB J 21:3329-3337

19. Lewis RA, Yagi N, Kitchen MJ, Morgan MJ, Paganin D, Siu KK, Pavlov K, Williams I, Uesugi K, Wallace MJ, Hall CJ, Whitley J, Hooper SB 2005 Dynamic imaging of the lungs using X-ray phase contrast. Phys Med Biol 50:5031-5040

20. Lachmann B, Grossmann G, Nilsson R, Robertson B 1979 Lung mechanics during spontaneous ventilation in premature and fullterm rabbit neonates. Respir Physiol 38:283-302

21. Vyas H, Field D, Milner AD, Hopkin IE 1986 Determinants of the first inspiratory volume and functional residual capacity at birth. Pediatr Pulmonol 2:189-193

22. Vyas H, Milner AD, Hopkins IE 1981 Intrathoracic pressure and volume changes during the spontaneous onset of respiration in babies born by cesarean section and by vaginal delivery. J Pediatr 99:787-791

23. Milner AD, Saunders RA, Hopkin IE 1978 Is air trapping important in the maintenance of the functional residual capacity in the hours after birth?. Early Hum Dev 2:97-105

24. Boon AW, Milner AD, Hopkin IE 1979 Lung expansion, tidal exchange, and formation of the functional residual capacity during resuscitation of asphyxiated neonates. J Pediatr 95:1031-1036

25. Milner AD, Sauders RA 1977 Pressure and volume changes during the first breath of human neonates. Arch Dis Child 52:918-924

26. Saunders RA, Milner AD 1978 Pulmonary pressure/volume relationships during the last phase of delivery and the first postnatal breaths in human subjects. J Pediatr 93:667-673

27. Karlberg P, Cherry RB, Escardo FE, Koch G 1962 Repiratory Studies in Newborn Infants. II: pulmonary ventilation and mechanics of breathing in the first minutes of life, including the onset of respiration. Acta Paediatr 51:121-136

28. Mortola JP, Fisher JT, Smith JB, Fox GS, Weeks S, Willis D 1982 Onset of respiration in infants delivered by cesarean section. J Appl Physiol 52:716-724

29. Probyn ME, Hooper SB, Dargaville PA, McCallion N, Crossley K, Harding R, Morley CJ 2004 Positive end expiratory pressure during resuscitation of premature lambs rapidly improves blood gases without adversely affecting arterial pressure. Pediatr Res 56:198-204

30. Probyn ME, Hooper SB, Dargaville PA, McCallion N, Harding R, Morley CJ 2005 Effects of tidal volume and positive end-expiratory pressure during resuscitation of very premature lambs. Acta Paediatr 94:1764-1770

31. O'Donnell C, Davis P, Morley C 2004 Positive end-expiratory pressure for resuscitation of newborn infants at birth. Cochrane Database Syst Rev 4:CD004341

32. Finer NN, Carlo WA, Duara S, Fanaroff AA, Donovan EF, Wright LL, Kandefer S, Poole WK 2004 Delivery room continuous positive airway pressure/positive endexpiratory pressure in extremely low birth weight infants: a feasibility trial. Pediatrics 114:651-657

33. Enhorning G, Robertson B 1972 Lung expansion in the premature rabbit fetus after tracheal deposition of surfactant. Pediatrics 50:58-66

34. Enhorning G, Grossman G, Robertson B 1973 Effect of tracheal deposition of surfactant on air expansion of lungs-study on premature rabbit fetuses. Arch Dis Child 48:162 